\title{
Fire Probability, Fuel Treatment Effectiveness and Ecological Tradeoffs in Western U.S. Public Forests
}

\author{
Jonathan J. Rhodes ${ }^{1}$ and William L. Baker ${ }^{*}, 2$ \\ ${ }^{I}$ Planeto Azul Hydrology, PO Box 15286, Portland, Oregon 97293, USA \\ ${ }^{2}$ Ecology Program and Department of Geography, Dept. 3371, 1000 E. University Ave., University of Wyoming, \\ Laramie, Wyoming 82071, USA
}

\begin{abstract}
Fuel treatment effectiveness and non-treatment risks can be estimated from the probability of fire occurrence. Using extensive fire records for western US Forest Service lands, we estimate fuel treatments have a mean probability of $2.0-7.9 \%$ of encountering moderate- or high-severity fire during an assumed 20 -year period of reduced fuels.
\end{abstract}

\section{INTRODUCTION}

Fuel treatments to reduce fire impacts have been promoted as a public forest restoration priority by policy [1] and the Healthy Forests Restoration Act of 2003. It is difficult to generalize about the effectiveness of fuel treatments under all conditions $[2,3]$, but treatments are not universally effective when fire affects treated areas [4]. Factors influencing effectiveness include forest type, fire weather [4], and treatment method [5].

However, treatments cannot reduce fire severity and consequent impacts, if fire does not affect treated areas while fuels are reduced. Fuels rebound after treatment, eventually negating treatment effects $[3,6]$. Therefore, the necessary, but not sufficient, condition for fuel treatment effectiveness is that a fire affects a treated area while the fuels that contribute to high-severity fire have been reduced. Thus, fire occurrence within the window of effective fuel reduction exerts an overarching control on the probability of fuel treatment effectiveness. The probability of this confluence of events can be estimated from fire records. Although this probability has not been rigorously analyzed, it has often been assumed to be high [7].

The probability of future fire occurrence also abets assessing the ecological risks incurred if fuels are not treated. Therefore, analysis of the likelihood of fire is central to estimating likely risks, costs and benefits incurred with the treatment or non-treatment of fuels.

Assessing fire occurrence and its effect on fuel treatment effectiveness also has merit because treatments can incur ecological costs, including negative impacts on aquatic systems [8], soils [7], and invasion by non-native plants [9, 10]. Here, we use watershed and aquatic systems as a specific context for evaluating tradeoffs involved with treatment and non-treatment of fuels on western public lands. However, the analysis applies to upland ecosystems as well.

The effects of fire on watersheds and native fish vary with several biophysical factors, including watershed and

*Address correspondence to this author at the Ecology Program and Department of Geography, Dept. 3371, 1000 E. University Ave., University of Wyoming, Laramie, Wyoming 82071, USA; E-mail: bakerwl@uwyo.edu habitat conditions, the condition of affected populations, and fire severity and extent [11]. If treatments reduce the watershed impacts of severe fire, they may provide benefits that outweigh treatment impacts because high-severity fire can sometimes trigger short-term, severe erosion and runoff [12] that can negatively affect soils, water quality, and aquatic populations. However, fuel treatments can also have impacts on aquatic systems. The magnitude and persistence of these treatment impacts vary with treatment methods, location, extent and frequency.

Although some fuel-treatment methods could have lower impacts, ground-based mechanical treatments are often employed because other methods generate activity fuels [7] and are more costly. Ground-based methods and associated machine piling, burning of activity fuels, construction and increased use of roads and landings can increase soil erosion, compact soils, and elevate surface runoff $[8,13,14]$. Although the effects of prescribed fire on watersheds are typically limited and fleeting, it can increase soil erosion and sediment delivery, sometimes significantly and persistently [15], especially if fires escape and burn larger and more severely than planned.

When impacts are extensive, proximate to streams, or in terrain with erosion hazards, treatments can increase runoff and sediment delivery to streams. Road activities that increase sediment production, such as elevated road traffic, often affect stream crossings where sediment delivery is typically efficient and difficult to control [16]. Elevated sediment delivery to streams contributes to water quality degradation that impairs aquatic ecosystems [17].

The extent and frequency of treatments may be significant. Stephens and Ruth [18] suggested treating fuels on 9.4 million ha, or $\sim 53 \%$ of USFS lands in the Pacific Northwest and California. Agee and Skinner [7] suggested repeating treatments every 10-20 years, due to transient effects on fuels.

Repeated treatments increase the potential for cumulative effects on aquatic ecosystems due to the persistence and additive nature of watershed impacts over time [19] and may increase the establishment of non-native plants [9]. The chronic watershed impacts from repeated treatments may be more deleterious to native fish than pulsed disturbances from wildfires [8]. 
Additional degradation of aquatic habitats on public lands may hamper efforts to protect and restore aquatic biodiversity. These habitats are increasingly important as cornerstones for restoring aquatic ecosystems and native fish [14].

Where fuel treatments might incur soil and watershed impacts, the risks from treatment and non-treatment should be assessed [7]. Although the respective impacts of treatments and fire are influenced by numerous factors, the occurrence of fire strongly affects the net balance between costs and benefits. If fire does not affect treated areas while fuels are reduced, treatment impacts on watersheds are not counterbalanced by benefits from reduction in fire impacts.

We provide a framework for quantitatively bounding the potential effectiveness of fuel treatments and the likelihood of fire affecting untreated watersheds, based on the probability of fire and the duration of treatment effects on fuels. This can be used to help statistically estimate the expected value associated with treatments or non-treatment based on the probability of possible outcomes and their associated costs and benefits [20]. Previous assessments of watershed tradeoffs from treatment and non-treatment $[21,22]$ did not include these in quantifying risk to aquatic systems associated with treatment versus non-treatment of fuels.

We use geographically-explicit data on fire on public lands in the western US to estimate, at a broad-scale, the probability that fuel treatments will be affected by fire during the period when fuels have been reduced. We also estimate the risk of higher severity fire occurring in watersheds if fuel treatments are foregone. These estimates provide a broad-scale bounding of treatment effectiveness and potential return from the fiscal and environmental costs of fuel treatments.

\section{METHODS}

\section{The Analytical Model}

Our analysis is based on the simple conceptual framework that unless fire occurs while fuels are reduced, fuel treatments cannot affect fire severity. We examine the probability of discrete classes of fire severity because fire impacts on watersheds vary with severity [11]. For instance, lower-severity fire has minimal, transient watershed impacts [11].

Future fire occurrence in specific locations cannot be predicted with certainty, but its probability can be estimated from empirical data. The probability of fire of a particular severity affecting treated areas can be estimated using the standard formula for the probability of an event occurring during a specific time frame:

$q=1-(1-p)^{n}$

where $q$ is the probability that a fire that would be of a specific severity in the absence of treatment occurs within $n$ years, $p$ is the annual probability of fire of a specific severity at the treatment location, and $n$ is the duration, in years, that treatments decrease fuels and can reduce fire severity. In Equation 1, $q$ provides an estimate of the mean fraction of an analysis area likely to burn at a specific severity within a given time frame in the absence of fuel treatments, which also represents the upper bound of potential effectiveness of treatments in reducing fire, since treatments cannot lower fire severity unless a fire occurs.

Both $n$ and $p$ can be estimated from available data. The duration of post-treatment fuel reduction, $n$, likely varies regionally with factors affecting vegetation re-growth rates, but fuels in western U.S. forests generally return to pretreatment levels in 10-20 years [3, 7]. To estimate the upper limit of treatment effectiveness, we assume $n=20$ years. We estimated the annual probability of fire of various severities, $p$, for each analysis area based on standard methods [23]:

$p=\left(F^{*} r\right) /(A * D)$

where $p$ is the annual probability of fire of a specific severity, $F$ is total area burned at any severity within the analysis area over the duration of the data record, $r$ is the estimated fraction of $F$ that burned at the specified severity over the analysis area, $A$ is the total analysis area, and $D$ is the total duration of the data record, in years.

We based our estimates of the annual probability of fire on post-1960 fire records rather than reported natural fire return intervals for two primary reasons. First, evidence indicates that natural fire regimes no longer operate in many forests, because of direct fire suppression and indirect changes in fuels from livestock grazing, logging and fire exclusion [24]. Annual burned area has also increased in some forest types, likely due to climatic warming [25]. Recent fire data ostensibly integrate these alterations, reflecting how fires are likely to burn in the near future under current conditions and management. Natural fire return intervals do not capture these alterations. Second, there is considerable uncertainty regarding the accuracy of reported natural fire intervals $[23,24]$. However, we stress that our approach can easily accommodate alternate estimates of annual fire probability using more geographically-refined data or where management changes might alter future fire probability.

We confined analysis to USFS lands in 11 western states, the focus for most proposed fuel treatments on public lands. The probability of fire varies geographically with several factors, including weather, ignition, fuels, and forest types. To bracket this effect, we estimated the annual probability of high-severity fire, $p$, for ( $i$ ) all landcover types and (ii) more frequently burning ponderosa pine (Pinus ponderosa) forests at the scale of U.S. Forest Service (USFS) administrative regions that are the finest scale at which extensive data allow estimation of fire severity. We focus on high-severity fire, but also analyze fires of broader severity, including (1) either high- or moderate severity and (2) any severity.

Our estimates represent an initial, broad-scale first approximation of the potential of fire to affect areas within a given time frame, based on the assumption that fire and treatments are random. Although fire is not random, data are insufficient to accurately quantify more local patterns. Our approach provides a valid mean result at our scale of analysis, based on data from more than 40,000 fires across the western U.S. Site-specific data could be used in future, local studies where the probability of fire is known to depart considerably from the regional mean. Ideally, fuel treatments may not be randomly located, but instead focused in areas where fire is most likely. However, this is not assured by current policy [26]. Widely used methods for assessing the risk of high-severity fire may have limited accuracy [27]. 
Therefore, our analysis assumes random treatment location, as a first approximation.

\section{West-Wide Analysis}

To provide a broad-scale perspective of potential fuel treatment efficacy, we estimated mean annual probability, $p$, of fire for all USFS lands in the 11 western U.S. states, excluding Alaska, for the entire duration that data on total annual fire area are available (1960-2006). Data on fire area from 1993-2003, reported by agency ownership [28], were used to estimate mean annual fraction of total fire area on USFS lands, which was extrapolated to estimate mean annual fire area on USFS lands from 1960-1993 and 20042006, for which fire area data were reported [29], but not by agency ownership. Annual fire area on USFS lands in the 11 western states was assumed proportional to the fraction of total USFS area in these states. Total number of fires on western USFS lands from 1960-2006 is not reported, but based on the foregoing areal partitioning, the fire area data are from several hundred thousand fires on western USFS lands. The estimated annual fire area on these western USFS lands from 1960-2006 was summed to yield $F$ in Equation 2.

The fraction of total fire area, $r$, that burned at high severity and high-moderate severity was estimated from data in USFS burned area emergency rehabilitation reports (BAER) for 470 fires in the 11 western states from 1973-1998 in six western USFS regions [30].

\section{Regional Analysis of Fire in Ponderosa Pine}

Because ponderosa pine forests are a key forest with more frequent fire, we estimated the mean annual probability of fire by severity in these forests on USFS lands: 1) on a regional basis, in six western USFS regions; and 2) Westwide. We used geographical information system (GIS) data for 40,389 fires in these forests for the entire period of data availability, 1980-2003 (Fig. 1). Data were in a GIS point dataset, containing burned area for each fire, maintained by the Bureau of Land Management [31] and derived from a systematic National database [32]. We quality controlled these data for our study area, removing a few duplicate records.

A GIS map of ponderosa pine forests was obtained by selecting codes 5-7 (ponderosa pine) in the Westgap map from the GAP program, which includes national vegetation mapping from satellite imagery [33]. A GIS map of U.S. Forest Service regions is from the agency [34]. We converted all maps to Albers projection, Clarke 1866 datum, then used these to extract all fire records $(n=40,389)$ for ponderosa pine forests on USFS land in the 11 western states. We used USFS maps to subset fires by region, and then: $(i)$ areas of individual fires were summed to yield $F$ in Equation 2; (ii) the GIS was used to obtain $A$, and (iii) fire severity data by USFS region from 1973-1998 [30] were used to estimate $r$ by severity.

\section{RESULTS AND DISCUSSION}

\section{West-Wide Analysis}

For the period 1960-2006, an estimated mean of $\sim 220,000$ ha, or a decimal fraction of 0.0037 of USFS western lands burned annually at any severity. Despite the approximations involved, our estimate of the mean annual frac- tion of areas burning at any severity compares reasonably with independent estimates by falling between them. Fire of any severity annually burned a mean fraction of $\sim 0.0014$ of the Deschutes National Forest in Oregon, from 1910-2001 [35], and $\sim 0.0046$ of 11 national forests in the Sierra Nevada, California, based on data from 1970-2003 [36].

Together with fire severity data [30], our West-wide estimate yields an estimated mean annual probability, $p$, of 0.001 and 0.002 for high- and high-moderate severity fire, respectively (Table 1). Based on these estimates of $p$, Equation 1 yields a probability, $q$, of 0.020 and 0.042 , respectively, for high- and high-moderate-severity fire. Substituting space for time, our results indicate that, on average, approximately 2.0 to $4.2 \%$ of areas treated to reduce fuels are likely to encounter fires that would otherwise be high or high-moderate severity without treatment. In the remaining $95.8-98.0 \%$ of treated areas, potentially adverse treatment effects on watersheds are not counterbalanced by benefits from reduced fire severity. These results also provide an estimate of the likelihood of high-severity fire affecting forests, if fuels are untreated. On average, over a 20 -year period, about $2.0-4.2 \%$ of untreated areas would be expected to burn at high or high-moderate severity, respectively.

Using Equation 1, our results indicate that if treatments were repeated every 20 years across all USFS lands in the West, it would take about 720 years (36 cycles of treatments), on average, before it is expected that high-severity fire affects slightly more than $50 \%$ of treated areas while fuels are reduced. Treatments would have to be repeated at 20 -year intervals for 340 years ( 17 cycles of treatments) before high-moderate severity fire is expected to encounter more than $50 \%$ of treated areas. Even after this duration of repeated treatments, it is likely that almost $50 \%$ of treated areas will be cumulatively affected by repeated treatments without compensatory benefits from reduced fire severity.

These West-wide estimates provide perspective, but include forest types, such as subalpine forests, typified by lowfrequency, high-severity fire, where fuel treatments are unlikely to encounter fire [4]. Other forests, such as ponderosa pine, burn more often.

\section{Regional Analysis of Ponderosa Pine}

For ponderosa pine forests, the probability, $q$, of treated areas being affected within their window of effectiveness varies regionally from 0.020 to 0.040 for high-severity fires and from 0.042 to 0.079 for high-moderate severity fires (Table 1). As expected, $q$ in these forests is higher than for the West-wide analysis of all cover types. The highest probabilities, as expected, are in the Southwest and in the Northern Rockies, with its dry summers (Table 1).

In these forests with more frequent fire, it is likely that fuel treatments can potentially reduce fire severity on a small fraction of treated areas. The results (Table 1) indicate that in $92.1-98.0 \%$ of treated areas, fuel treatment impacts on watershed processes are not likely to be counterbalanced by a reduction in higher-severity fire.

Across the six regions, treatments would have to be repeated every 20 years for 340 to 700 years ( 17 to 35 times), on average, before it is expected that high-severity fire affects more than $50 \%$ of treated areas during periods of treat- 


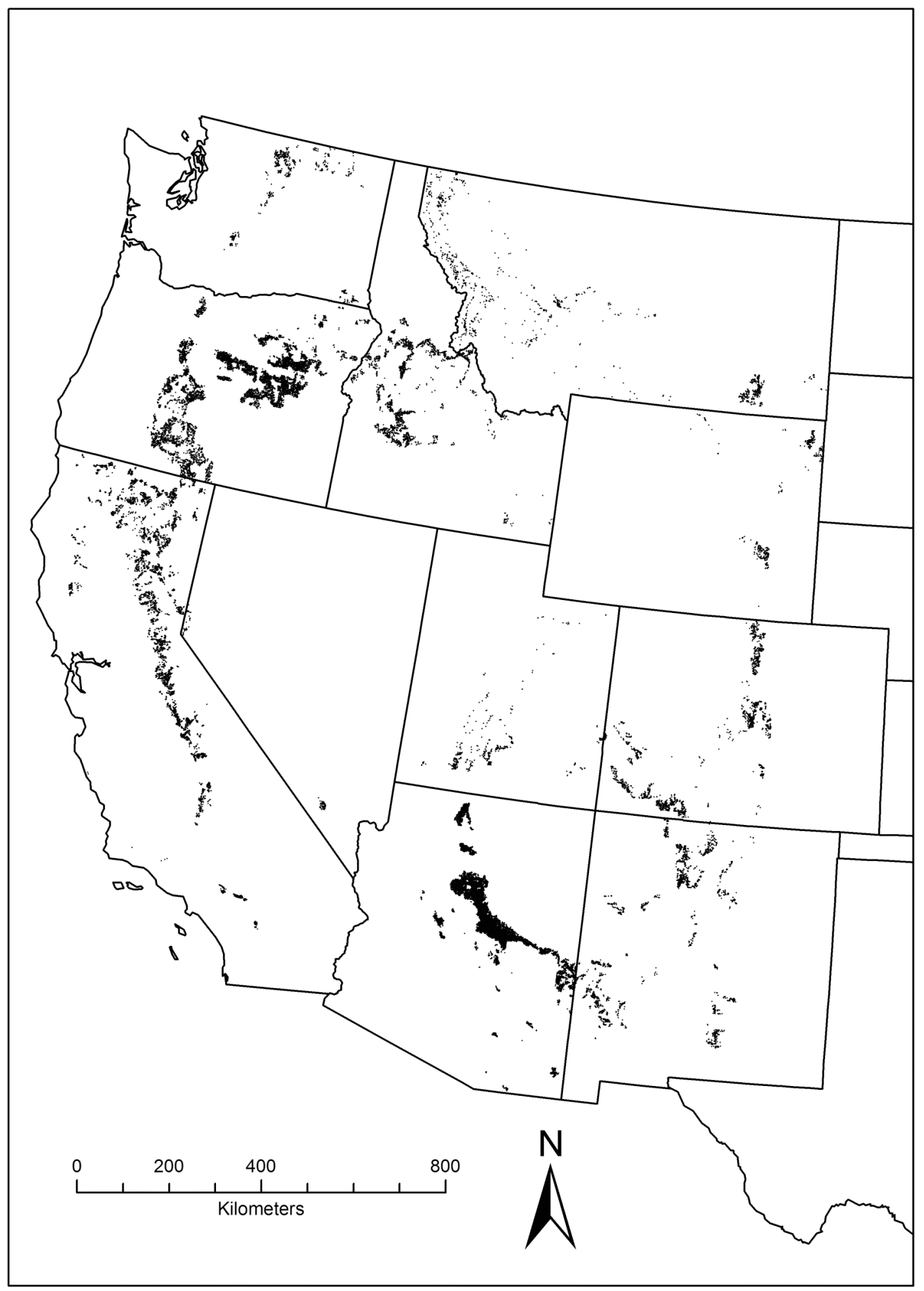

Fig. (1). Ponderosa pine forest fires $(n=40,389)$ in the western United States from 1980-2003. This is the dataset used in the regional analysis.

ment effectiveness. Treatments would have to be repeated for 180 to 340 years ( 9 to 17 times) before more than $50 \%$ of treated areas are expected to be affected by high-moderate severity fire. On average, these repeated treatments would affect watersheds and, potentially aquatic systems, depending on treatment practices, without providing reduction in fire severity on almost $50 \%$ of treated area.
An alternative method for estimating the risk of fire in the absence of fuel treatments is to use the fire rotation rather than mean annual probability of fire. The fire rotation indicates how long it takes, on average, for a particular area to burn one time and how often fire may return to a particular point in the landscape [23]. The fire rotation is calculated by: $\mathrm{B}=1 / \mathrm{p}$ 
Table 1. Estimated $p$ and $q$ for Fires in Ponderosa Pine (PIPO) Forests. Data are Shown for Three Fire Severity Classes by USFS Region, and for All Forests on USFS Lands West-Wide

\begin{tabular}{|c|c|c|c|c|c|c|}
\hline \multirow{2}{*}{ USFS Region } & \multicolumn{2}{|c|}{ Any Severity } & \multicolumn{2}{|c|}{ High-Moderate Severity } & \multicolumn{2}{|c|}{ High Severity } \\
\hline & $\mathbf{p}$ & $\mathbf{q}$ & $\mathbf{p}$ & $\mathbf{q}$ & $\mathbf{p}$ & $\mathbf{q}$ \\
\hline $1 \mathrm{~N}$. Rockies & 0.0070 & 0.1311 & 0.0036 & 0.0693 & 0.0020 & 0.0402 \\
\hline 2 C\&S Rockies & 0.0059 & 0.1116 & 0.0041 & 0.0786 & 0.0014 & 0.0269 \\
\hline $3 \mathrm{SW}$ & 0.0053 & 0.1008 & 0.0025 & 0.0487 & 0.0016 & 0.0307 \\
\hline 4 Gt. Basin & 0.0090 & 0.1654 & 0.0037 & 0.0715 & 0.0013 & 0.0257 \\
\hline 5 Calif. & 0.0046 & 0.0881 & 0.0031 & 0.0603 & 0.0017 & 0.0338 \\
\hline $6 \mathrm{NW}$ & 0.0037 & 0.0715 & 0.0022 & 0.0421 & 0.0010 & 0.0198 \\
\hline West-wide: PIPO & 0.0054 & 0.1026 & 0.0031 & 0.0602 & 0.0015 & 0.0295 \\
\hline $\begin{array}{l}\text { West-wide: All } \\
\text { types }\end{array}$ & 0.0037 & 0.0715 & 0.0021 & 0.0416 & 0.0010 & 0.0203 \\
\hline
\end{tabular}

where $B$ is the fire rotation for fire of a specific severity and $p$ is, again, the mean annual probability of fire of a specific severity.

Based on our analysis, the mean annual probability, $p$, of high-severity fire in ponderosa pine forests West-wide is 0.0015 (Table 1), implying a fire rotation, $B$ of about 667 years, varying from 500 to 1,000 years among individual regions. Based on the results in Table 1, the fire rotation for high-moderate severity fire is about 323 years in ponderosa pine forests West-wide, varying from 244 to 454 years in individual regions, based on data in Table 1 . These results suggest that western ponderosa pine forests are not currently being rapidly burned by high or high-moderate severity fire, counter to other previous work [37].

\section{Relaxing the Assumptions and Some Caveats}

In some cases, the occurrence of fire of any severity may be of interest. Such cases include areas where fire of any severity might lead to high-severity fire. In ponderosa pine forests, the probability of fire of any severity encountering treatments within 20 years is approximately $7.15-16.5 \%$ across the six regions (Table 1). Thus, if it is assumed that fuel treatments that encounter fire of any severity might be effective, the results indicate fuel treatments, on average, would not have the potential to reduce fire impacts on aquatic systems in $83.5-92.8 \%$ of the area treated. Based on Equation 1 and Table 1, treatments would have be repeated every 20 years for $80-200$ years, on average, before fire of any severity affects more than $50 \%$ of the treated areas in ponderosa forests in these USFS administrative regions.

However, the assumption that treatments that encounter low-severity fire convey benefits may not be warranted. Low-severity fires are commonly and easily extinguished under current management whether or not they encounter fuel treatments. Further, low-severity fire has minimal adverse impacts on watershed processes while conveying benefits, including maintenance of forest structure and fuel levels.

Our probabilistic approach does not explicitly address factors that can strongly influence fire area and severity, such as fuel conditions. Although spatially-explicit modeling of fire behavior can directly investigate the effects of such conditions, such models are unlikely to provide accurate estimates of the probability of occurrence of fire of a given severity because a host of other factors that influence fire area and severity cannot be deterministically predicted, including the frequency and location of ignitions and weather conditions during fire. Methods of assessing the risk of highseverity fire that are primarily based on fuel conditions have been shown to be an ineffective predictor of the actual severity at which fires burn [38]. In contrast, extensive recent data from numerous fires, as used in our analysis, does provide a robust estimate of the mean probability of the occurrence of fire of a given severity, because it integrates the many factors that influence fire occurrence and severity.

Our estimates likely represent the upper bound for fuel treatment effectiveness at the scale of analysis. In many cases, less than $4.16-7.86 \%$ of treated area is likely to experience high-moderate severity fire during the duration of treatment effectiveness, because $q$ decreases with decreases in $n$, the duration of treatment effectiveness. This duration is often less than the 20 years assumed in our analysis. In the Sierra Nevada of California, fuels returned to pre-treatment levels within 11 years [39]. At the values of $p$ in Table $\mathbf{1}$, reducing $n$ from 20 to 11 years (Eq. 1 ) reduces the probability that higher-severity fire affects treatments by $\sim 5 \%$.

Moreover, fuel levels rebound after treatment, eventually negating potential treatment effectiveness. If the reduction in effectiveness over time is such that mean effectiveness over the duration, $n$, is half the initial degree of effectiveness, the probability that fuel treatments reduce high-severity fire is approximately half the value of $q$ for any value of $p$ and $n$ calculated using Equation 1.

Finally, available data indicate that fuel treatments do not always reduce fire severity when fire affects treated areas while fuels are reduced [4]. Our analysis does not address these effectiveness issues. For these combined reasons, Equation 1 likely estimates the upper bound of potential fuel treatment effectiveness in reducing fire impacts on aquatic systems.

Although our analysis focuses on higher-severity fire in bounding the effectiveness of fuel treatments and their net watershed effects, these fires do not have solely negative effects. Higher-severity fire benefits watersheds and aquatic 
ecosystems in several ways, including providing a bonanza of recruitment of large wood and pulsed sediment supply that can rejuvenate aquatic habitats and increase their productivity $[8,14]$. High severity fire is also a key process for the restoration of structural heterogeneity in forests, which is important for biodiversity [27, 40].

Our analysis intrinsically assumes some degree of climatic stationarity, which may not be warranted. Climatic variability influences the area annually burned in forests [25, 41]. However, the relatively recent fire data used in our regional analysis incorporates recent climatic fluctuation and possibly directional change, which would not be reflected in estimates based on natural fire return intervals. For instance, the data in our analysis of ponderosa pine forests come primarily from years in which annual fire area had increased due to climatic warming [25]. However, the analysis framework is flexible enough to accommodate projected values of the mean annual probability of fire, $p$, based on forecasts of climatic change or changes in fire management.

Current findings suggest treatment effects on fire severity are mostly confined to treated areas [3], but theory suggests a dense network of treatments might slow fire spread and reduce intensity, yielding a landscape-scale effect on fire severity [42]. However, empirical evidence of severity reduction was seen in the lee of only three of several dozen treatments in two Arizona wildfires [43]. Nonetheless, if dense treatment networks are shown to work in the future, our approach can aid in estimating their costs and benefits, because fire must still affect treated areas while fuels are reduced for networks to reduce fire severity.

\section{CONCLUSIONS}

Our analysis provides West-wide and regional first approximation of the likely upper bound of fuel treatment effectiveness. While valid at these two scales, they are not applicable to all smaller analysis areas, due to spatial variation in annual fire probability. However, the framework is flexible enough to allow more spatially explicit analyses of $q$ where local estimates of $n$ and $p$ are available. The framework allows analysis of uncertainty, by using a range of plausible values for $n$ and $p$. The analysis can also estimate the number of treatments to reach a specified $q$, abetting estimation of cumulative effects on ecosystems from repeated treatments.

Our approach also provides a method for quantitatively assessing the imminence of high-severity fire effects in the absence of fuel treatments and the degree of urgency of response. Based on available data, these are shown to be much lower than previously estimated in some work [37].

Our results and analyses can improve the assessment of risks to watersheds inherent in the treatment or nontreatment of forest fuels, because it accounts for the probability of fire and the transient nature of fuel treatments. For instance, previous work [22], evaluating treatment and nontreatment impacts, assessed the risks associated with fuel treatments based on the assumption that a single treatment significantly reduces fire risk on all treated areas, subsequently reducing consequent watershed impacts from fire. Other evaluations of these tradeoffs [21] compared the erosional effects of fuel treatments with high-severity fire under the explicit assumption that high-severity fire was inevitable without treatment and the implicit assumption that treatments always reduce or eliminate the potential for highseverity fire. Our analysis indicates that these assumptions are unwarranted and likely mischaracterize the outcomes and associated impacts of treatment options.

The approach can be extended to aid in assessing the risk to other ecosystem elements and processes that may be adversely affected by either fuel treatments or high-severity fire. For instance, non-native vegetation can be influenced by high fire severity [44] and some fuel treatments [10], especially if the treatments are repeated [9].

Even in ponderosa pine forests that burn relatively frequently, our regional analysis indicates that after 17 cycles of treatments, only slightly more than $50 \%$ of treated areas could potentially have fire severity reduced, on average. Our results indicate that high-severity fire is far from inevitable in areas left untreated and is, instead, expected to affect only a relatively small fraction of such areas at the broad scale of our analysis. Factoring in the probability of fire, using our framework, can significantly improve the assessments of the risks posed to aquatic systems by treating or not treating forest fuels. Where site-specific data on fire probabilities exist, the framework can be used to help locate treatments where they are most likely to encounter higher severity fire, increasing the likelihood of treatment benefits. In fact, our results indicate that such efforts are crucial.

There are several important factors that influence the aquatic tradeoffs among fuel treatments, fire, and aquatic systems that our framework does not address. Although the probability of outcomes is critical to assessing the expected value of options, the ecological costs of the outcomes of treatment $v s$ non-treatment are also important in assessing the expected value of these options. With respect to the aquatic context, there is an ongoing need to fully evaluate tradeoffs such as the severity and persistence of the negative and positive impacts on watersheds and aquatic populations from fuel treatments and higher severity fire [8, 45]. An additional related issue is how effective treatments are when they encounter fire under a broad array of conditions affecting fire behavior [3]. While our analysis does not address these factors, it refines evaluation of net impacts of fuel treatment $v s$ non-treatment by providing a framework for estimating the likelihood of fire occurrence in a given time frame.

At the scales of our analysis, results indicate that even if fuel treatments were very effective when encountering fire of any severity, treatments will rarely encounter fire, and thus are unlikely to substantially reduce effects of high-severity fire.

\section{ACKNOWLEDGEMENTS}

We thank Susan Goodman of the Bureau of Land Management for compiling and distributing the fire history database, Andrew Westerling for discussion of historical fire history records, the Pacific Rivers Council for funding aspects of the initial research on this topic, and three anonymous reviewers for their helpful comments on the manuscript. 


\section{REFERENCES}

[1] U.S. Department of Agriculture. A collaborative approach for reducing wildland fire risks to communities and the environment: 10 -year comprehensive strategy implementation plan [monograph on the internet]. Washington: U. S. Department of Agriculture; 2002 [cited 2006 Feb 11. Available from: http://fireplan.gov/.

[2] Pollet J, Omi PN. Effect of thinning and prescribed burning on crown fire severity in ponderosa pine forests. Inter J Wildl Fire 2002; 11: 1-10.

[3] Graham RT, McCaffrey S, Jain TB, Eds. Science basis for changing forest structure to modify wildfire behavior and severity RMRS-GTR-120. Fort Collins: USDA Forest Service Rocky Mountain Research Station; 2004.

[4] Schoennagel T, Veblen TT, Romme WH. The interaction of fire, fuels, and climate across Rocky Mountain forests. BioScience 2004; 54: 661-76.

[5] Raymond C, Peterson DL. How did prefire treatments affect the Biscuit fire? Fire Manage Today 2005; 65: 18-22.

[6] Kauffman JB. Death rides the forest: perceptions of fire, land use, and ecological restoration of western forests. Conserv Biol 2004; 18: 878-82.

[7] Agee JK, Skinner CN. Basic principles of forest fuel reduction treatments. Forest Ecol Manage 2005; 211: 83-96.

[8] Rieman B, Lee D, Burns D, et al. Status of native fishes in the western United States and issues for fire and fuels management. For Ecol Manage 2003; 178: 197-211.

[9] Dodson EK, Fiedler CE. Impacts of restoration treatments on alien plant invasion in Pinus ponderosa forests, Montana. J Applied Ecol 2006; 43: 887-97.

[10] Merriam, KE, Keeley JE, Beyers JL. The role of fuel breaks in the invasion of nonnative plants, US Geological Survey scientific investigations report 2006-5185. Reston: US Geol Survey; 2007.

[11] Gresswell RE. Fire and aquatic ecosystems in forested biomes of North America. Trans Amer Fish Soc 1999; 128: 193-221.

[12] Allen CD, Savage M, Falk DA, et al. Ecological restoration of southwestern ponderosa pine ecosystems: A broad perspective. Ecol Appl 2002; 12: 1418-33

[13] Reid LM, Dunne T. Sediment production from forest road surfaces. Water Resour Res 1984; 20: 1753-61.

[14] Karr JR, Rhodes JJ, Minshall GW, et al. The effects of postfire salvage logging on aquatic ecosystems in the American West. BioScience 2004; 54: 1029-33.

[15] Megahan, WF, King JG, Seyedbagheri KA. Hydrologic and erosional responses of a granitic watershed to helicopter logging and broadcast burning. For Science 1995; 41:777-95.

[16] Kattlemann R. In: Sierra Nevada Ecosystem Project: Final report to Congress, vol. II, Assessments and scientific basis for management options. Davis: University of California Centers for Water Wildl Resour 1996; 855-920.

[17] Waters TF. Sediment in streams: sources, biological effects, and control. Bethesda: Amer Fish Soc; 1995

[18] Stephens SL, Ruth LW. Federal forest-fire policy in the United States. Ecol Appl 2005; 15: 532-42.

[19] Ziemer RR, Lewis J, Lisle TE, Rice RM. Long-term sedimentation effects of different patterns of timber harvesting. In: Proceedings of the symposium on sediment and stream water quality in a changing environment: Trends and explanation Inter Assoc Hydrol Sci Publ no. 203; 1991: Wallingford, UK: Inter Assoc Hydrol Sci; 1991; pp. $143-50$.

[20] Benjamin JR, Cornell CA. Probability, statistics, and decision for civil engineers. $3^{\text {rd }}$ ed. New York: McGraw-Hill; 1970

[21] Elliot WJ, Miller IS. Estimating erosion impacts from implementing the National Fire Plan. In: Annual International Meeting Am Soc Agric Eng; 2002; Chicago, IL: Am Soc Agric Eng; 2002; meeting paper 025011 .

[22] O'Laughlin J. Conceptual model for comparative ecological risk assessment of wildfire effects on fish, with and without hazardous fuel treatment. For Ecol Manage 2005; 211: 59-72.
[23] Baker WL, Ehle D. Uncertainty in surface-fire history: the case of ponderosa pine forests in the western United States. Can J For Res 2001; 31: 1205-26.

[24] Veblen TT. Key issues in fire regime research for fuels management and ecological restoration. In P. N. Omi, and L. A. Joyce, eds. Proceedings of conference on fire, fuel treatments, and ecological restoration RMRS-P-29; 2002: Fort Collins:USDA Forest Service Rocky Mountain Research Station; 2003; pp. 259-75.

[25] Westerling AL, Hidalgo HG, Cayan DR, Swetnam TW. Warming and earlier spring increases western U.S. forest wildfire activity. Science 2006; 313:940-3.

[26] U.S. Department of Agriculture Office of Inspector General. Audit report: Implementation of the Healthy Forests Initiative USDA/OIG-A/08601-6-AT. Washington: USDA Office of Inspector General; 2006.

[27] Odion DC, Hanson CT. Fire severity in conifer forests of the Sierra Nevada, California. Ecosystems 2006; 9: 1177-89.

[28] National Interagency Fire Center [homepage on the Internet]. [Cited 2005 March 8] Available from: http://www.nifc.gov/fire info/fires acres.htm

[29] National Interagency Fire Center [homepage on the Internet] [Cited 2007 October 13] Available from: http://www.nifc.gov/fire info/fires acres.htm

[30] Robichaud PR, Beyers JL, Neary DG. Evaluating the effectiveness of postfire rehabilitation treatments RMRS-GTR-63. Fort Collins: USDA Forest Service Rocky Mountain Research Station; 2000

[31] U.S. Department of Interior Bureau of Land Management. 2003. [cited 2006 February 11] Fire History Database: Available from: ftp://ftp.blm.gov/pub/gis/wildfire/firehistory2003.

[32] U.S. Department of Agriculture Forest Service. NIFMID: National Interagency Fire Management Integrated Database - technical reference manual. Washington: USDA Forest Service, Fire and Aviation Management; 1993.

[33] U.S. Department of Interior Geological Survey. 2005. Gap analysis data warehouse: [cited $2006 \mathrm{Feb} 11$ ]. Available from: gapanalysis.nbii.gov/portal/server.pt

[34] U.S. Department of Agriculture, Forest Service. 2005. Geodata Clearinghouse: Available from: svinetfc4.fs.fed.us [cited 2006 February 11$]$.

[35] Finney MA. The challenge of quantitative risk analysis for wildland fire. Forest Ecol Manage 2005; 211: 97-108.

[36] U.S. Department of Agriculture Forest Service. Sierra Nevada forest plan amendment final supplemental environmental impact statement. San Francisco: USDA Forest Service; 2004.

[37] Covington WW. Helping western forests heal: the prognosis is poor for US forest ecosystems. Nature 2000; 408: 135-6.

[38] Odion DC, Hanson CT. Fire severity in the Sierra Nevada Revisited: Conclusions robust to further analysis. Ecosystems In Press.

[39] van Wagtendonk JW, Sydoriak CA. Fuel accumulation rates after prescribed fires in Yosemite National Park. In: Proceedings of $9^{\text {th }}$ conference on fire \& forest meteorology; 1987: San Diego; Am Meteor Soc 1987; pp. 101-5.

[40] Noss, RF, Franklin JF, Baker WL, Schoennagel T, Moyle, PB. Managing fire-prone forests in the western United States. Front Ecol Environ 2006; 4: 481-7.

[41] Whitlock C, Shafer SL, Marlon J. The role of climate and vegetation change in shaping past and future fire regimes in the northwestern US and the implications for ecosystem management. For Ecol Manage 2003; 178: 5-21.

[42] Finney MA. Design of regular landscape fuel treatment patterns for modifying fire growth and behavior. Forest Sci 2001; 47: 219-28.

[43] Finney MA, McHugh CW, Grenfell IC. Stand- and landscape-level effects of prescribed burning on two Arizona wildfires. Can J For Res 2005; 35: 1714-22.

[44] Keeley JE, Lubin D, Fotheringham CJ. Fire and grazing impacts on plant diversity and alien plant invasion in the southern Sierra $\mathrm{Ne}-$ vada. Ecol Appl 2003; 13: 1355-74.

[45] Rhodes JJ, Odion DC. Evaluation of the efficacy of forest manipulations still needed. BioScience 2004; 54: 980. 